\title{
MINERÍA DE COBRE EN EL OCCIDENTE DEL MÉXICO PREHISPÁNICO: UN ACERCAMIENTO HISTORIOGRÁFICO
}

\author{
POR \\ JOSÉ ALFREDO URIBE SALAS (1) \\ Universidad Michoacana de San Nicolás de Hidalgo
}

El desconocimiento de la cultura metalúrgica tarasca ha llevado a omisiones insostenibles, lo mismo que a afirmaciones desproporcionadas y a errores históricos. Este ensayo historiográfico insiste sobre la cultura metalúrgica tarasca, que se caracterizó, en el contexto mesoamericano, por el amplio conocimiento de los metales, particularmente en la confección de objetos de cobre y sus aleaciones, superior a aquellas regiones en donde se trabajaron metales nativos como el oro y la plata.

\section{INTRODUCCIÓN}

Quizá por la indiscutible y desbordante presencia indígena en México, Guatemala, Ecuador, Perú y Bolivia, y a su profunda y poderosa relación con la naturaleza, conozcamos hoy algunos de los elementos culturales de mayor trascendencia del pasado prehispánico. Sin duda, elementos de una época histórica, pero raíz incuestionable del saber y del entramado científico moderno. Aludimos en esta ocasión, por supuesto, a la explotación y uso de los metales, al desarrollo del conocimiento metalúrgico alcanzado por las comunidades andinas y mesoamerịcanas; a la

(1) Becario de CONACYT, México, para realizar estudios de doctorado en España. 
importancia que tuvieron los metales en la vida y en el desarrollo social y económico de estos pueblos; a su papel e influencia en las concepciones religiosas y espirituales mucho antes del arribo de los españoles al nuevo continente.

Por mucho tiempo, el sistema colonial y la cultura dominante trataron de borrar todo vestigio del pasado prehispánico. Entre 1492 y 1521 se inició no sólo la destrucción material del mundo indígena, también de sus culturas y representaciones cosmogónicas: sus ideas de los hombres, la sociedad y el universo (2). Han tenido que transcurrir alrededor de cuatro siglos para que se iniciaran las primeras pesquisas en torno a la explotación y usos de los metales del pasado prehispánico. Desde luego, los testimonios y crónicas de los conquistadores han servido de hilo conductor a los primeros y subsiguientes estudios; algunos, muy pocos, de los documentos pictográficos indígenas que han llegado hasta nuestros días, y los frutos de los trabajos arqueológicos y etnohistóricos realizados en los siglos xvIII y xIx. El interés mayor sobre este aspecto del pasado precolonial, corresponde al presente siglo. Gracias a la publicación en 1992

(2) No tratamos de incitar a la polémica, sino de consignar los resultados de las investigaciones más representativas. La compilación de documentos históricos es una tradición antigua, puesta en práctica por los primeros misioneros. Por ejemplo, en la Nueva España, que es lo que conocemos mejor, la recolección y estudio de documentos pictográficos escritos en las lenguas aborígenes o traducidos al castellano recibieron un impulso por parte de Juan de Tovar, Toribio de Motolinía y Bernardino de Sahagún, que en la segunda mitad del siglo XVI fue obstaculizada y prohibida por la Corona española. En 1577 Felipe II, enterado de la basta reunión de documentos y tradiciones indígenas emprendida por Sahagún, ordenó al virrey Enríquez requisar la documentación reunida, ordenándole que «con mucho cuidado y diligencia procuréis haber estos libros y sin que dellos quede original ni traslado alguno, los enviéis a buen recaudo en la primera ocasión a nuestro Consejo de las Indias, para que en él se vean; y estaréis advertido de que por ninguna manera persona alguna escriba cosa que toquen a supersticiones y manera de vivir que estos indios tenían en ninguna lengua». Según los especialistas, el olvido que sepultó los trabajos de los primeros cronistas había sido decidido, ordenado y preparado con la expresa voluntad de ocultar para siempre el recuerdo de sus escritos y los temas que ellos habían tratado. Ver: Robert RICART, La conquista espiritual de México, México, Editorial Juspolis, 1947; Georges BAUDOT, Utopies et historie au Mexique, Privat, Toulouse, 1977, págs. 475-485; Enrique FloresCano, Memoria Mexicana. Ensayo sobre la reconstrucción del pasado: época prehispánica-1821, México, Editorial Joaquín Mortiz, 1987.

R. I., 1996, n. ${ }^{\circ} 207$ 
de la monumental obra en cuatro volúmenes editada y coordinada por Juan Manuel López, Ignacio González Casasnovas y Esther Ruiz de Castañeda Minería Iberoamericana. Repertorio Bibliográfico y Biográfico (3), podemos tener una visión de conjunto sobre esta temática. El registro de más de 50 trabajos, entre artículos y libros, publicados entre 1912 y 1992, nos indica el creciente interés de la comunidad académica y científica internacional por conocer y explicar el mundo de los metales entre los pueblos y culturas que sucumbieron con el inicio de la historia moderna y contemporánea.

Pero aún queda mucho por hacer. Es pertinente llamar la atención sobre la minería y la metalurgia tarasca que no ha sido cubierta en la obra antes mencionada, cuya zona de influencia se localizaba sobre la vertiente del Océano Pacífico, y que abarcaba al momento del contacto con los españoles el territorio del actual estado de Michoacán y parte de los de Colima, Guerrero, Guanajuato, Querétaro y Jalisco. El desconocimiento de la cultura metalúrgica tarasca ha llevado a omisiones insostenibles, lo mismo que a afirmaciones desproporcionadas y a errores históricos. Por ello el interés del presente ensayo historiográfico, que por otro lado está lejos de abarcar y agotar en el análisis el conjunto de estudios escritos hasta hoy día, sobre esta porción del territorio y de la cultura metalúrgica tarasca, que se caracterizó, en el contexto mesoamericano, por su amplio conocimiento metalúrgico, particulamente en la confección de objetos metalíferos de cobre y sus aleaciones, superior a aquellas regiones en donde se trabajaron metales nativos como el oro y la plata.

En relación con el presente acercamiento historiográfico al problema de la minería y la metalurgia entre los tarascos, hemos optado por apuntar brevemente, a manera de coordenadas históricas, algunos aspectos sustantivos de la cultura metalúrgica prehispánica en América, como contexto natural de nuestro análisis. Las referencias historiográficas no pretenden ser exhaustivas, pero sí representativas de las tendencias

(3) Juan Manuel López, Ignacio GonZález CASASNOvas y Esther RuIZ, Mineria Iberoamericana. Repertorio Bibliográfico y Biográfico, Madrid, Instituto Tecnológico de España/Consejo Superior de Colegios de Ingenieros de Minas de España/Sociedad Estatal V Centenario, 4 vols., 1992. 
actuales. Los siguientes apartados constituyen ejes analíticos obligados para evaluar el conocimiento alcanzado hasta el momento y puntos de partida para trabajos de mayor especialización multidisciplinarios.

\section{Cultura metalúrgica prehispánica en América}

No está demostrado aún si en el continente que hoy conocemos como América, el desarrollo de la metalurgia fue individual o si se trasmitió de una civilización a otra desde el exterior. Pero hay quienes opinan lo contrario y sostienen, sin aportar todavía elementos sólidos y convicentes, la presencia de una influencia del Viejo al Nuevo Mundo en una época no precisa, o inclusive del continente asiático (4). Desde luego, grupos de investigadores de muy diversos países y disciplinas, continúan laborando en esta dirección.

Lo cierto es que el uso del cobre estuvo limitado, por lo menos en su fase inicial, a los sitios donde el metal podía encontrarse como material de superficie en estado nativo y que por otra parte se inició en muy distintos lugares de la tierra y en diferentes épocas. De acuerdo con George Irving Quimby, los grupos indígenas que habitaron cerca de las orillas del Lago Superior de América del Norte, región rica en cobre nativo, ya lo utilizaban aproximadamente cinco mil años antes de nuestra Era. Otros señalan que el trabajo del cobre nativo data tan sólo de cuatro mil años antes de Cristo, o entre cinco mil y tres mil a.C. (5).

(4) Estos investigadores realizan un recuento de los estudios y evidencias que se han acumulado hasta nuestros días: George IRVING QuIMBY, Indian Life in the Upper Great Lakes, $11.000 \mathrm{BC}$ to $A D$. 1800, Chicago The University of Chicago Press, 1960; Jacquetta HawKes, History of Mankind. Cultural and Scientific Development, vol. 1, London, Mentor Book, 1965; H. LEHMANN, «Ancient methods of gilding silver: exemples from the old and New Worlds", Science and Archaelogy, Robert H. Brill, ed., Massachusetts Institute of Techology, 1971; Gordon CHILDEN, El origen de la civilización, México, 1979; Mariano CUESTA DOMingo y Salvador Rovira Llorens, Los trabajos de metal en el Área Andina, Madrid, Ministerio de Cultura/Museo de América, s.f.; D. M. K. GRINBERG, Los señores del metal. Minería y metalurgia en Mesoamérica, México, Consejo Nacional para la Cultura y las Artes/Pangea Editores, 1990.

(5) George IRving QuIMBY [4], págs. 6-8; Duley T. EASBY, "Early Metallurgy in the New World", Scientific American, april, 1966, pág. 73; Ramón PIÑA

R. I., 1996, n.o 207 
Pero los lugares en que según los especialistas se inició el uso del cobre, se localizan en el Viejo Mundo; en el Medio Oriente y únicamente en áreas que constituían una pequeñísima fracción de la superficie habitable del planeta. Según reportan los estudiosos, la más antigua se remonta a los cinco mil quinientos años antes de Cristo, y apareció en Anatolia e Irán, después en Mesopotamia, y en los valles del Nilo y del Indo (6).

Si como lo han señalado varios estudiosos los primeros ensayos metalúrgicos en el Viejo Mundo se remontan al quinto milenio antes de Cristo, con la cultura de Tell Halaf, en Mesopotamia (7), en América no tenemos evidencias de tales ensayos hasta el período Chavín, en el Perú septentrional, es decir, en el primer milenio antes de Cristo (8). El investigador Izumi Shimada ha señalado a Batán Grande, localizado precisamente en la costa septentrional del Perú, como el lugar donde se ha encontrado un importante centro de minería y beneficio del cobre cuyo desarrollo se remonta entre 600 y 1000 antes de Cristo (9).

Investigaciones recientes coinciden en un cuadro cronológico del desarrollo de la metalurgia prehispánica en América, antes de la llegada de los españoles. La cultura más antigua se remonta al año 800 a.C., y corresponde al área del Alto Perú (zona geográfica: Perú, Bolivia, norte de Argentina); le sigue el Bajo Perú, 700 a.C. (zona geográfica: costa del Perú, Ecuador); en tercer lugar aparece Colombia, 600 años a.C. (zona geográfica: Colombia, más interior de Ecuador); le sigue Centroamérica: 700-900 d.C. (zona geográfica: Centroaméricana); y por último, Mesoamérica: 700-900 d.C. (10).

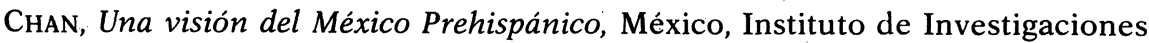
Históricas, Universidad Nacional Autónoma de México, 1967, págs. 26-29.

(6) Jacquetta Hawkes [4], págs. 429-430; Ralph LinTon, The Tree of Culture, New York, Vintage Books, 1961; Mischa TITIEV, The Science of Man, New York, Henry Holt and Co., 1959.

(7) M. OpPenheim, Tell-Yalat. I: Die Prahistorischen Funde, Berlín, Wallter de Gruyter, 1943; H. LehmanN [4].

(8) Existe una amplia bibliografía sobre este tópico, en: Juan Manuel LóPEZ, Ignacio GonZÁlez CASASNovas y Esther Ruiz DE CASTAÑEda [2].

(9) Izumi SHIMADA, "Temples of time. The ancient burial and relígious center of Batan Crande, Perú", Archaeology, vol. 34, N.o 5, 1981, págs. 41-45.

(10) Paul Rivet et Henry ARsandauX, "La Metalurgia en Amerique PreColombinne», Travaux et Memorias Institut d'Etnologia, vol. XVI, n.o XXXIX, Uni- 
¿Cómo se ha podido elaborar esta cronología? Dado que no se puede averiguar directamente la fecha en que se elaboró una pieza de metal, los objetos de metal son fechados en función de los objetos de cerámica que los acompañan, los que sí son fechables por medio de técnicas de laboratorio, mientras que para los metales no se dispone, hasta el momento, de una técnica convincente. Otra manera de saber su edad es cuando se los encuentra junto con trozos de carbón o madera. Estos últimos pueden ser fechados por una técnica llamada de fechamiento por carbono 14, lo que permite saber la fecha, por ejemplo, de un entierro, siempre dentro de un intervalo de error. Aquí radica la importancia del trabajo arqueológico y la intervención de expertos de muy distintas disciplinas.

De cualquier manera, con los elementos antes anotados, se ha podido demostrar un desfase cronológico del desarrollo tecnológico entre el Viejo y el Nuevo Mundo. Existe un criterio de periodización metodológico elaborado por los historiadores, para diferenciar la época anterior al registro escrito de los acontecimientos, es decir, anterior a la escritura.

Este período fue dividido en edad de piedra, edad de cobre, edad de bronce y edad de hierro, según el material con que los hombres fabricaban sus instrumentos de trabajo. Atenidos a estos criterios, los especialistas coinciden en afirmar que los pobladores de América se encontraban en la edad del bronce, es decir, anterior a la edad de hierro. El arqueólogo José Alcina Franch es contundente al señalar que «este desfase inicial de la metalurgia americana es el que llevará a los pueblos indígenas de ese continente, aún a los de más elevada cultura, a carecer de un instrumento suficientemente desarrollado y a tener que sustituirlo por el empleo de materiales que en el Viejo Mundo quedarán desechados muy pronto. Entendemos que buena parte de la explicación para el fulminante éxito de los españoles en la conquista de los más grandes imperios americanos -el de los Mexicas y el de los Incas- debe buscarse precisamente en el

versidad de París, Francia, 1946; Izumi SHIMADA [9], págs. 41-45; Mariano Cuesta Domingo y Salvador Rovira Llorens [4]; D. M. K., Grinberg, "Relaciones metalúrgicas en América Prehispánica. Criterios de aleación en el sistema oro-plata-cobre», Las fronteras de Mesoamérica, vol. 2, México, 1977, págs. 117-124; de la misma autora [4].

R. I., 1996, n. ${ }^{\circ} 207$ 
desequilibrado encuentro de dos tecnologías en tan diferente nivel de desarrollo» (11).

Existe una corriente muy extendida que señala que en América, y muy particularmente en el área mesoamericana, el empleo del cobre obtenido por fundición a partir de sus menas, estaba muy poco difundido a la llegada de los españoles. En lo general, se indica que "en América sólo podemos hablar de un bronce incipiente confinado a los dominios inca y (con reservas) azteca y maya, nacido poco antes de la presencia española. No se hace un uso amplio del bronce: a principios del siglo XVI incas y aztecas siguen dependiendo en gran medida de los instrumentos líticos; tampoco aparecen nuevos tipos instrumentales, limitándose a reproducir en bronce lo que normalmente hacían en piedra pulida o tallado" (12).

Es bastante raro encontrar en los estudios generales sobre uso y explotación de los metales en América prehispánica, alusión a la cultura metalúrgica tarasca. Hay sus excepciones, y éstas proceden más bien de la historiografía norteamericana. Por lo general, lo cual es comprensible, los expertos se han abocado al estudio de dos de las principales culturas precolombinas que tuvieron lugar en Mesoamérica: la Maya y la Azteca. A partir de los objetos metálicos encontrados en estas áreas, y a falta de datos sobre trabajo minero y técnicas metalúrgicas nativas, se ha concluido que por sus rasgos estilísticos, etcétera, prácticamente el grueso de los objetos de metal mesoamericano procede de Centro y Sudamérica.

Lo cierto es que apenas por el siglo IX d.C., los pueblos mesoamericanos conocieron la metalurgia propiamente dicha y la comenzaron a practicar. Queda de manifiesto así, como acertadamente resume Adolphus Langenscheidt (13), el desfasamiento técnico que había respecto de algunas culturas andinas

(11) José Alcina FRANCH, "La producción y el uso de metales en la América Precolombina", I Coloquio Internacional sobre Historia de la Minería. La minería hispana e iberoamericana, León, VI Congreso Internacional de Minería, 1970, vol. I, págs. 307-331.

(12) Esta opinión de los profesores Mariano CUESTA DoMINGo y Salvador Rovira LlORENS [4], ya fue ampliamente desarrollada a finales de la década de 1940 por Paul Rivet y Henry ARSANDAUX [10], págs. 52-172.

(13) Adolphus LANGENSCHEIDT, "Bosquejo de la minería prehispánica en México», Quipu, vol. 2, n. ${ }^{\circ}$ 1, enero-abril de 1985, págs. 27-57. 
y, sobre todo, del Viejo Mundo. Luego, el volumen de la producción fue en general relativamente pequeño; es decir, unos cuantos miles de toneladas fueron, en ocasiones, la producción de una mina durante varios siglos. Finalmente, es pertinente señalar que los incentivos que tenían los mineros y su actitud estaban influidos por sus ideas mágicas y religiosas, y por su organización y estructura social, y muy poco o nada por los conceptos de utilidad y rentabilidad económica y de productividad. Esta es la gran diferencia con la minería y la metalurgia del Viejo Continente.

El período arqueológico que los especialistas en la materia denominan clásico tardío, abarca aproximadamente desde el año 700 al 900 d.C. Fue la época en que sobrevino la ruina económica de Teotihuacán, y a la vez el auge de la gran urbe huasteca, El Tajín, así como el surgimiento de la ciudad de Tula y de la cultura tolteca, que marcó la evolución del sistema social teocrático a sistema militarista. Por tanto, podemos considerar que fue éste un tiempo de ajustes sociales y políticos que no permitieron avances considerables en la minería mesoamericana, aunque no podemos pasar por alto que fue también hacia final del período, es decir, por el año 900 d.C., cuando se introdujeron la metalurgia y desde luego la orfebrería, por las costas occidentales como lo veremos después (14), como un importante aporte cultural de los pueblos andinos que ya hacía varios siglos habían dominado tal tecnología. Es de creerse que, por lo menos localmente, hubo demanda de cobre y de los metales con los que se hacían sus ligas, como el oro, la plata, el estaño, el arsénico, el zinc y el plomo; si bien partiendo de sus minerales mixtos, en la mayor parte de los casos. Tal demanda debió influir en la actividad minera del occidente mesoamericano, desde Sinaloa hasta Oaxaca y quizá Chiapas, ya en la zona maya.

Más tarde, en el denominado período chichimeca, que cubrió aproximadamente desde el año 1200 al 1370 d.C., quedó caracterizado por el arribo y florecimiento del grupo chichimeca de Xólotl al valle de México, dentro de un contexto general mesoamericano de migraciones y desplazamientos de

(14) Idem.

R. I., 1996, n. 207 
gente que dieron origen a nuevos estados, desde luego de corte militarista, como ya era normal (15). Entre estos estados se constituyeron los purépechas o tarascos que fueron fuertes hasta la conquista española. Como es de esperarse, las zonas en lás que la metalurgia y la orfebrería se desarrollaron más, como fueron Michoacán y Oaxaca, tuvieron actividades mineras más amplias y diversas que el resto del territorio mesoamericano, donde el patrón de producción debió seguir siendo el tradicional, aunque sufriendo los trastornos que fueron causando las migraciones de pueblos bárbaros. En los estados de Michoacán y Oaxaca el desarrollo fue básicamente de minerales de cobre, oro y plata. Los especialistas han estimado que los pueblos de otras zonas, menos favorecidos con tal riqueza de minerales metálicos, se los procuraron por comercio (16).

Los mexicas, a pesar de su poderío extendido por una zona del área mesoamericana, se inclinaron más por el comercio y por la imposición de un sistema tributario, que por la producción directa de los materiales y productos elaborados que aprovechaban. No sabemos de minas explotadas propiamente por

(15) De las principales obras en donde se puede estudiar en profundidad aspectos variados de la evolución de la sociedad mesoamericana, destacan las de Pedro CARrasco, Johanna Broda, et al., Estratificación social en la Mesoamérica prehispánica, México, SEP-INAH., 1976; Brigitte BOEHM DE LAMEIRAS, Formación del estado en el México prehispánico, Zamora, Colegio de Michoacán, 1986; Andrés MEdinA, Alfredo LóPEZ Austin, et al., Origen y formación del estado en Mesoamérica, México, Universidad Nacional Autónoma de México, 1986.

(16) Adolphus LANGenscheidt [13], Paul KirchHoff, "La relación de Michoacán como fuente para la historia de la sociedad y cultura Tarasca», Estudio preliminar a Relaciones de Michoacán, Madrid, Ediciones Aguilar, S.A., 1956; Jenaro GonZÁlez ReYnA, Riqueza Minera y Yacimientos Minerales en México (Monografías Industriales del Banco de México, S.A.), México, Banco de México, 1947; Marcia Castro Leal, Tzintzuntzan. Capital de los tarascos, Morelia, Gobierno del Estado de Michoacán, 1986; S. GoRENSTEIN I y H. P. PoLLAR, The Tarascan Civilization: a Late Prehispanic Cultura System, Nashville, Tennessee, Vanderbitt University Publications in Anthropology 28, 1983; Dorothy Hosler, The Origins. Technology and Social Construction of Ancient West Mexican Metallurgy, Ph. D. Dissertation, Department of Anthropology, University of California, Santa Bárbara, 1986; D. LóPEz SARrelangue, La nobleza indigena de Pátzcuaro en la época Virreinal, México, Universidad Nacional Autónoma de México, 1965. 
los mexica, excepto las de obsidiana cercanas a Teotihuacán, que habían sido trabajadas por tantos otros pueblos más antiguos, advirtiendo que su intervención en las explotaciones bien pudo ser como supervisores (17).

\section{La sociedad tarasca en el Occidente de México. LA ARQUEOLOGÍA, LOS TRABAJOS ETNOHISTÓRICOS Y LOS OBJETOS DE METAL}

Para los tiempos del contacto con los españoles, una gran porción de la parte occidental del actual territorio de México estaba bajo el control del estado tarasco. Etnólogos, arqueólogos, antropólogos e historiadores han abordado diferentes aspectos de su origen y evolución, su cultura, su economía y de su organización interna. Desde Nicolás León, pasando por Paul Kirchhoff, David Brand, Robert West, H. P. Pollard, J. B. Warren, S. Gorenstein y D. López Sarrelangue, entre otros, han hecho aportaciones sustanciales al conocimiento de esta región y han desvelado muchos de sus aspectos económicos, sociales, políticos y culturales (18).

Sin embargo, los estudios sobre la explotación y uso del mineral cuprífero son relativamente recientes. A partir del último cuarto del siglo XIX, cuando el cobre se colocó entre los metales de creciente demanda mundial, comenzó a documentarse esta cuestión, y se despertó el interés entre nacionales y extranjeros. Fue precisamente en 1877, en el marco del Congreso Internacional de Americanistas, celebrado en Luxemburgo, cuando se desató una acalorada polémica sobre si

(17) D. M. K. GRINBerg [10], págs. 117-124; Adolphus LANGENSCheidT [13], págs. 27-57.

(18) Nicolás León, Los Tarascos, México, Museo Nacional, 1903; Paul KIRCHHOFF, "Los tarascos y sus vecinos según las fuentes del siglo XVI", Actas y Memoiras del XXVII Congreso Internacional de Americanistas, México, tomo II, 1939; Donald BRAND "An Historical Sketch of Geography and Anthropology in the Tarascan Region", New Mexico Anthrologist, VI-VII, 1943, págs. 37-108; Robert WEST, Cultural Geogrphy of the Modern Tarascan Area, Institute of Social Anthropology, 7, Smithsonian Institution, Washington, D.C., 1948; Helen Perlstein Pollard, Prehispanic Urbanism aty Tzintzuntzan, Michoacan, PH.D. dissertation, Department of Anthropology, Columbia University, 1972; J. B. Warren, La Conquista de Michoacán, 1521-1530, Morelia, Fimax Publicistas, 1977; Gorenstein y H. P. Pollard [16]; D. López Sarrelague [16].

R. I., $1996, \mathrm{n} .{ }^{\circ} 207$ 
los pueblos precolombinos mesoaméricanos conocían o no los elementos básicos de la ciencia metalúrgica, o bien, si se encontraban en una etapa anterior al uso de los metales. El barón Federico de Hallwald, representante de Austria-Hungría, rebatió la tesis de un ponente latinoamericano que sostenía que los pueblos prehispánicos conocían, extraían y beneficiaban el mineral mucho antes del arribo de los europeos al nuevo continente. Señaló Hallwald, a modo de conclusión, que "no existe en México ninguna señal de la explotación de las minas de cobre por los indígenas, con anterioridad al descubrimento de América» (19).

La polémica no hubiera trascendido los marcos del evento, de no ser por la respuesta dada ese mismo año por el profesor Jesús Sánchez, entonces director interino del Museo Nacional (hoy Museo Nacional de Antropología e Historia, Ciudad de México), en la que rebatió la visión etnocéntrica europea de Hallwald que calificaba a los pueblos aborígenes de Mesoamérica de primitivos, y consideraba a sus culturas como productos inferiores del desarrollo humano. En un artículo titulado «El Congreso Internacional de Americanistas en Europa y el cobre entre los Aztecas»(20), Jesús Sánchez argumentó, apoyándose en documentos de la colección Boturini (21), que

(19) Jesús SÁNCHEZ, «El Congreso Internacional de Americanistas en Europa y el cobre entre los Aztecas", Anales del Museo Nacional de México, época 1, vol. 1, México, 1877, págs. 387-395; Santiago RAMírez, Noticias históricas de la riqueza minera de México, y de su actual estado de explotación, México, Secretaría de Fomento, 1884.

(20) Jesús SÁNCHEZ [19], págs. 388-394.

(21) Se sabe que las primeras colecciones de documentos reunidas por Juan de Torquemada, Carlos de Sigüenza y Góngora y Agustín de Betancourt, fueron las que alentaron la curiosidad de Lorenzo de Boturini, viajero italiano que entre 1736 y 1743 residió en Nueva España y emprendió una búsqueda persistente de códices y testimonios escritos que en siete años lo convirtieron en poseedor de la colección más rica de documentos sobre México antiguo que se habían reunido en Nueva España. Cuando Boturini tomó la iniciativa de promover la coronación de la Virgen de Guadalupe sin obtener antes el consentimiento y apoyo de las autoridades, cayó en desgracia y perdió la valiosa colección de documentos que había formado. Por mandato del virrey esta colección fue enviada a España y depositada en la Real Academia de la Historia, donde permanece. Los escritos de Boturini Bernaducci fueron publicados en 1746 y por Manuel BALlesteros GaIBrois en 1948 (Madrid, Colección Documentos Inéditos para la Historia de Espãna) y 1992 (México, UNAM). Copias de estas Colecciones quedaron en custodia de la 
los pueblos indígenas mesoamericanos debieron conocer las técnicas metalúrgicas para trabajar diversos minerales, entre ellos el cobre, y cuyos productos estaban profundamente arraigados en la vida cotidiana y económica de los mismos. Así lo mostraban los datos sobre la matrícula de los tributos que los pueblos sometidos al imperio azteca entregaban periódicamente a la nobleza, entre los que se encontraban hachas de cobre. La respuesta convenció a muy pocos y abrió el debate; las interrogantes se multiplicaron, antes que disminuir.

El empuje industrial que tenía lugar en Europa y en los Estados Unidos de Norteamérica, y que demandó mayores volúmenes de este mineral, estimuló en los círculos académicos y científicos el interés por redoblar los estudios geológicos, minerológicos y a profundizar en el pasado para determinar en qué momento y en qué región de México se había iniciado la explotación, y cuál era el nivel de los conocimientos metalúrgicos alcanzados al momento de la llegada de los españoles.

A poco de que comenzaron a explotarse los depósitos cupríferos de El Boleo (Baja California) y Cananea (Sonora), por inversionistas franceses y norteamericanos en la década de 1860, algunos especialistas mexicanos, ingenieros de minas egresados del Colegio de Minería, emprendieron los primeros trabajos de reconocimiento y explotación en otras regiones del país. En 1881 y 1884, José C. Haro y Santiago Ramírez (22), discípulo este último del sabio minerologista español Andrés Manuel del Río, dieron a la luz pública los frutos de sus estudios, concluyendo que uno de los mayores criaderos de cobre de México, se localizaba en la región occidente del país, es decir, en el espacio geográfico comprendido por los actuales estados

Secretaría del Archivo del Virreinato. Consumada la independencia en 1821, el gobierno de Agustín de Iturbide ordenó que el Archivo Histórico resguardado en la antigua Secretaría del Virreinato se trasladara al Ministerio de Estado y del Despacho de Relaciones Interiores y Exteriores, y se creara un Museo. Es decir, todos los documentos históricos sobre el virreinato, y las colecciones formadas por Boturini volvieron a integrarse a un solo fondo. En 1877 el nuevo museo estaba integrado por tres departamentos: Historia Natural, Arqueología e Historia; ese mismo año se crearon las secciones de Antropología y Etnografía. Años después, Gumersindo MENDOZA y Jesús SÁNCHEZ publicaron el primer "Catálogo de las colecciones histórica y arqueológica del Museo Nacional de México», Anales del Museo Nacional, México, 1882, págs. 445-486.

(22) Santiago RAMirez [19].

R. I., 1996, n. 207 
de Guerrero, Michoacán y Colima. De paso, insinuaron, sin abundar en el tema, que el metalífero bien pudo haber sido explotado desde tiempos muy remotos, anterior a la Conquista.

Aunque los frutos de los estudios de Haro y Ramírez tuvieron en ese' momento pocas repercusiones, sirvieron para que tiempo déspués arqueólogós y etnólogos de diferentes nacionalidades interesados en el pasado prehispánico, aventuraran las primeras hipótesis sobre la explotación y uso del cobre entre los tarascos antes que los españoles al mando de Hernán Cortés penetraran en la parte occidental del futuro virreinato de la Nueva España. La primera evidencia fue sin duda, la existencia de abundantes yacimientos de cobre dentro de los antiguos dominios tarascos. Pero con ello, desde luego, no se avanzó gran cosa. La segunda fue la que proporcionó el naturalista Nicolás León como resultado de sus pesquisas realizadas a finales del siglo XIX y principios de éste, cuando dio a conocer los primeros estudios etnohistóricos sobre el Estado. y la sociedad tarasca (23). En él, apenas toca lo concerniente al cobre, reforzó la tesis anterior y avanzó nuevas ideas sobre los conocimientos que parecían tener los tarascos sobre otros minerales como el oro y la plata, en poder de éstos: dice "que cuando los españoles solicitaron oro al emperador tarasco, éste mandaba buscar de un tesoro, situado en una de las islas del lago de Páztcuaro, media luna de plata y discos de oro que tenía guardados» (24).

Con el correr de los años se agregaron nuevos elementos. La Revolución Mexicana de 1910, y con ella la efervescencia social y la agitación política, abrieron el camino a los sectores oprimidos como protagonistas históricos. El logro mayor, y uno de los más importantes de las ciencias sociales del siglo $\mathrm{xx}$, como resultado del movimiento revolucionario, fue haber crea-

(23) Nicolás LEón, "Las Yácatas de Tzintzuntzan», Anales del Museo Michoacano, Morelia, 1888, págs. 65-70; del mismo autor [18]; Los Tarascos, notas históricas, étnicas y antropológicas, México, Imprenta del Museo Nacional, 1904, y "Los indios tarascos del lago de Pátzcuaro», Anales del Museo Nacional de Arqueología, Historia y Etnografía, 5. época, n.o 1, México, 1934, págs. 149-169.

(24) Nicolás León [18]; Miguel León PoRTILla, «Minería y metalurgia en el México Antiguo", La Minería en México, México, Universidad Nacional Autónoma de México, 1978. 
do un concepto antropológico e histórico que reconoció el carácter original de las diversas culturas mesoamericanas, y a partir de este reconocimiento discurrir enfoques idóneos para comprender su desarrollo dentro de su propio marco histórico y cultural. Manuel Gamio, Alfonso Caso, Miguel Othón de Mendizábal, entre otros, crearon una nueva dimensión de la antropología para estudiar el desarrollo de estas culturas y fundaron las instituciones, las disciplinas, las escuelas, los museos, las bibliotecas y los laboratorios para realizar esta tarea de manera sistemática y progresiva. En esta época se sembraron las bases de la arqueología científica y se promovió un diálogo permanente entre arqueólogos, etnólogos e historiadores para examinar el desarrollo de las antiguas civilizaciones (25).

Desde finales de los años veinte, transcurrida la etapa armada del movimiento revolucionario, pero sobre todo en las décadas de 1930 a 1950, se efectuaron numerosas exploraciones arqueológicas en las principales zonas del país financiadas por las nuevas instituciones oficiales y académicas. En Michoacán, cuna de la sociedad tarasca, los primeros resultados de las pesquisas las dieron a conocer sus autores entre 1931 y 1939. En estos años, estudiosos de la talla de Alfonso Caso, Jorge Acosta, Eduardo Noguera, Daniel Rubín de la Borbolla e Isabel Kelly (26), dieron a la luz pública los primeros artículos que

(25) José Lameiras, "La antropología en México. Panorama de su desarrollo en lo que va del siglo", Ciencias Sociales en México. Desarrollo y perspectivas, México, El Colegio de México, 1979, págs. 108-180; Miguel León PorTilla, "Perspectivas de la investigación sobre la historia prehispánica de México", Historia Mexicana, XXI, octubre-diciembre, 1971, págs. 198-216; Leonardo MANRIQUE y Yólotl LESUR, "Historia prehispánica de México», Veinticinco años de investigación histórica en México, México, El Colegio de México, 1966, págs. 375-403; Enrique FloRESCANO, Los estudios económicos sobre la época prehispánica, México, Departamento de Investigaciones. Históricas del INAH.; del mismo autor. El nuevo pasado mexicano, Editorial Cal y Arena, 1991.

(26) Alfonso CASO, "Informe preliminar de las exploraciones realizadas en Michoacán", Anales del Museo Nacional de México, época IV-VI, México, 1930, págs. 440-452; Jorge AcosTA, "Exploraciones arqueológicas realizadas en el Estado de Michoacán durante los años 1937-1938», R.M.E.A., vol. III, n. ${ }^{\circ} 2$, México, 1939, págs. 85-98; Eduardo NoGUERA, «Exploraciones en las regiones de Zamora y Pátzcuaro, Estado de Michoacán", Anales del Museo Nacional de México, México, época IV, 1931, tomo III, págs. 84-103; del mismo autor, "Exploraciones en 'El Opeño', Michoacán", Actas y Memorias del XXVII Congreso Internacional de Americanistas, México, vol. I, págs. 574-586; Daniel RUBÍN DE 
daban cuenta de la presencia de abundantes objetos y artefactos metálicos, encontrados en tumbas y lugares ceremoniales. Pero aún era temprano para discernir si eran el resultado de una metalurgia propia, o como ya sugerían algunos estudiosos (27), fruto del intercambio comercial sudamericano. Aquí imperó el criterio de que, dicho en palabras del profesor Mariano Cuesta Domingo, no siempre la presencia de objetos metálicos en un contexto estatigráfico es suficiente prueba para confirmar que se trata de una cultura metalúrgica. Estos objetos, como se ha podido ver en otros casos, pueden haber sido obtenidos mediante comercio o botín. Por tanto, mientras no se disponga de pruebas confirmatorias como son los restos de hornos, crisoles o cubiletes, moldes, deshechos de fundición, etc., conviene ser cautos, especialmente si nos movemos dentro de probables fases de transición.

Con el correr de los años, se agregaron nuevos elementos. En las décadas siguientes, aunque continuaron con mayor brío las exploraciones arqueológicas, y se acrecentó igualmente el número y la variedad de los artefactos metálicos, la orientación de las investigaciones comenzaron a transitar de la mera acumulación y descripción de los mismos, al estudio del contexto cultural y, muy particularmente, al análisis de las técnicas metalúrgicas y al registro de las influencias habidas desde el exterior mediante el estudio comparativo entre la naturaleza y semejanza con otros pueblos y culturas. En 1940, Pedro R. Hendrichs dio a conocer un extenso estudio sobre las técnicas mineras prehispánicas; cuatro años después, Daniel Rubín de la Borbolla publicó un ensayo sobre la orfebrería tarasca.

LA BORBOLLA, "Antropología Tzintzuntzan-Ihuatzio, Temporada I y II", R.M.E.A., tomo III, n.o 2, México, 1939, págs. 99-121; del mismo autor, "Arqueología Tarasca", El Occidente de México, 4. a Mesa Redonda de la S.M.A., México, 1948, págs. 30-35; Isabel KELLY, "An Archacological reconnaissance of the cast coast Nayarit to Michoacan", Actas y Memorias del XXVII Congreso Internacional de Americanistas, México, tomo II, 1939, pág. 77; de la misma autora, "Excavations at Apatzingán, Michoacán», Publications in Antropology, n. ${ }^{\circ}$ 7, New York, Viking Fund, 1947.

(27) Los resultados parciales de los etnólogos franceses Paul RIVET y Henry ARSANDAUX [10], tuvieron en estos años una influencia creciente entre los estudiosos mesoamericanistas abocados a analizar las influencias sudamericanas sobre la cultura de Mesoamérica. 
Antes de terminar la década de los cuarenta, McLeod hizo una aportación al conocimiento de la realidad en cuestión, a través de un meticuloso artículo en donde analiza una gran cantidad de artefactos metálicos encontrados ese mismo año por el arqueólogo Robert $\mathrm{H}$. Lister en la región de Cojumatlán, Michoacán (28).

Posteriormente, en los años cincuenta y sesenta, aparecieron los estudios de Donald Brand, Paul Wastheim, David Pendergast, J. Mountjoy, J. B. Warren y María Luisa Horcasitas. Las evidencias mostraron que, aunque los objetos de metal estaban presentes en muchas áreas de Mesoamérica, el metal era más ampliamente utilizado en la región occidental. Las evidencias arqueológicas y la documentación etnohistórica de estos años, aunadas a los logros alcanzados en las décadas siguientes, corroboraron el hecho de que para la época de la conquista española el metal jugaba un papel significativo en varios campos de la cultura nucleada en torno del estado tarasco. Los objetos metálicos incluyen un número de diferentes clases de implementos utilitarios y una variedad de elementos simbólicos o de estatus (29).

Marcia Castro Leal proporciona en su trabajo (30) una rela-

(28) Pedro Hendrichs, "Datos sobre la técnica minera prehispánica», El México Antiguo, tomo V, varios números, México, 1940-1941; Daniel RuBín DE lA Borbolla, "Orfebrería Tarasca», Cuadernos Americanos, n.o 3, México, 1944, págs. 125-138; MCLAOD, "Analysis of metal artificts», Excavations al Cojumatlan, Michoacán, México, Publications in Anthropology, n. ${ }^{\circ}$, University of New México, 1949; Robert H. LISTER, "Summary of Excavations of Cojumatlán, Michoacán", El Occidente de México, 4. ${ }^{a}$ Mesa Redonda de la S.M.A., México, 1948, págs. 26-27; del mismo autor, "Excavations of Cojumatlán, Michoacán", Publications in Antropology, n.o. 3, University of New México, 1949.

(29) Donald BRAND, «Bosquejo histórico de la geografía y la antropología en la Región Tarasca", Anales del Museo Michoacano, n. ${ }^{\circ}$ 5, segunda época. Morelia, 1952, págs. 49-163; Paul Wastheim, Arte Antiguo de México, Méxıcu, Fondo de Cultura Económica, 1950; David PENDERGAST, "Metal Artefacts in Prehispanic Mesoamerica», American Antiquity, vol. 27, n. ${ }^{\circ} 4$, Manasha, Wisconsin, 1962, págs. 520-545; J. MounTJOY, "On The Origen of Mexican Metallurgy", Mesoamerican Studies, n. ${ }^{\circ}$ 4, University Museum, Southern Illinois University, Carbondale 1969, págs. 26-42; María Luisa HoRCASITAS, Una Artesania con raíces prehispánicas en Santa Clara del Cobre, Michoacán, México, Departamento de Etnohistoria/Instituto Nacional de Antropología e Historia, 1981.

(30) Marcia Castro Leal [16].

R. I., 1996, n. ${ }^{\circ} 207$ 
ción de los principales objetos de metal hallados en diferentes temporadas de trabajo arqueológico en la región tarasca (agujas, ajarcas, alfileres, alambres, anzuelos, anillos, argollas, azadas, barras con colgantes en los extremos, bezotes, brazaletes, cascábeles, casquillos, cuentas, discos, figurillas, hachas, orejeras, pinzas, punzones, vasijas, etc.), y señala el lugar de su procedencia, descripción de sus características exteriores, y la función social a que estaban destinados principalmente. El lector podrá notar en él la preponderancia del análisis arqueológico y etnohistórico, de modo que predomina una percepción aún burda de las técnicas metalúrgicas y poca alusión a las aleaciones. Fue común, entonces, considerar los objetos metálicos como de cobre, oro y plata, y casi nunca producto de un trabajo metalúrgico especializado.

\section{FACTORES CONSTITUTIVOS DEL FENÓMENO METALÚRGICO EN LA CULTURA TARASCA}

La mayoría de los especialistas como Francisco del Paso y Troncoso, Eduardo Seler, Othón de Mendizábal, Wilberto Jiménez Moreno, José Corona Núñez, Salvador Mateos y Dora M. Krasnopolsky de Grimberg, entre otros, coinciden en señalar que ni los códices -pictografías de carácter histórico- (31), ni los relatos de los conquistadores y primeros cronistas son suficientes por sí sólos para entender acerca de la manera de cómo los indígenas obtenían los minerales, pues los datos son vagos o imprecisos. A pesar del pregonado interés de los conquistadores españoles por el oro y otros metales preciosos al llegar al

(31) Francisco Del Paso y Troncoso, "Lienzo de Jucutacato", Exposición histórico-americana de Madrid, Catálogo de la Sección de México, México, tomo I, págs. 245-249; José CoRona NúÑEZ, Lienzo de Jucutacato, México, Editorial Vargas Rea, 1943; Miguel OTHON DE MENDIZÁBAL, "El Lienzo de Jucutacato, su verdadero significado", Obras Completas, México, 1946, tomo II, págs. 89-118; Wilberto Jiménez MoReno, "Historia Antigua de México», El Occidente de México, México, Sociedad Mexicana de Antropología, 1948, págs. 146-157; D. M. K. de GRINBERG, «El legajo 1204 del Archivo General de la Nación, el Lienzo de Jucutacato y las minas prehispánicas de cobre de Ario, Michoacán", Norte y Occidente de México, México, Universidad Nacional Autonóma de México, 1986. 
Nuevo Mundo, no son muchas las descripciones y referencias en las crónicas, a las minas y placeres indígenas, o al trabajo para la obtención de los metales que tanto interesaban (32). Otros estudiosos añaden que se sabe poco de las minas y de las habilidades metalúrgicas de los antiguos habitantes de este continente debido, en la mayoría de los casos, a que los datos de que disponemos provienen del relato de los comentaristas españoles que no tenían los conocimientos técnicos para entender y describir, de manera clara, las técnicas que veían utilizar a los indígenas (33). O bien, que los mismos indios no les proporcionaran información al respecto (34).

Lo cierto es que por mucho tiempo los especialistas no tuvieron noticias ni información confiable, o las que existían no estaban lo suficientemente contrastadas para fundamentar que los habitantes del occidente de México conocían y explotaban sus propias minas. La presencia de abundantes objetos de metal como parte de la cultura tarasca, no resolvió por sí mismo el problema en cuestión. Por el contrario, ganó terreno la hipótesis de una influencia sudamericana promovida por investigadores franceses de la talla de Paul Rivet, Henry Arsandaux y André Clément, entre otros, llevada al extremo recientemente por Adam Szaszdi Nagy, en el sentido de que dicha influencia comprendía no sólo la importación de los conocimientos y habilidades, sino también las materias primas, esto es, los metales (35).

Las incógnitas comenzaron a despejarse como resultado del trabajo arqueológico efectuado en las décadas de 1940 y 1950. Fue debido a los trabajos arqueológicos de Pedro R. Hendrichs, quien descubrió una mina cercana al Cerro del

(32) José Alcina Franch [11], págs. 307-331.

(33) D. M. K. GRINBERG [4], pág. 23.

(34) María Luisa Horcasitas de BarRos [29], pág. 39.

(35) Henry ARsandaux et Paul Rivet, "Contribution a l'éstude de la métallurgie mexicaine», Journal de la Société des'Americanistes de París, París, 1921, tomo XVII, págs. 262-280; André ClEMENT, "Note sur la dureté des haches précolombiennes de l'Equateur et du Mexique», Journal de la Societé des'Americansites de París, París, 1932, tomo XXIV, págs. 84-91; Adam SzASZDI NAGY, Un mundo que descubrió Colón. Las rutas del comercio prehispánico de los metales, Valladolid, Publicaciones de La Casa-Museo de Colón y Seminario Americanista de la Universidad de Valladolid, 1984. 
Águila, en el actual Estado de Guerrero. Por sus características y objetos encontrados en el lugar, concluyó que se trataba de una mina prehispánica, la primera reportada hasta entonces. El instrumental lítico hallado en el sitio y en sus cercanías, permitió a los expertos llegar a la conclusión de que aparte de los minerales que encontraban a flor de tierra, hacían pozos y socavones de escasa profundidad, sin que supieran sostener las techumbres de ellos, por lo que tenían que abandonarlos en cuanto amenazaban derrumbarse. Las excavaciones en esta mina tenían tres metros y medio de longitud por un metro y medio de profundidad, orientadas sobre una veta de cobre que parecía tener aproximadamente de cuatro a diez centímetros de anchura. Hendrichs percibió señales en sus paredes de haber sido quemadas y resquebrajadas (36).

En estos mismos años, y en forma paralela, arqueólogos, etnólogos y antropólogos desempolvaron y editaron diferentes documentos pictográficos, como el Lienzo de Jucutacato, lo mismo ocurrió con materiales de gran relevancia histórica como las Relaciones de Michoacán (1541) y las Relaciones Geográficas de la Diócesis de Michoacán (1579-1580), que en el contexto de los avances historiográficos de la época, abrieron nuevas perspectivas de análisis (37). Es decir, los hallazgos arqueológicos de Hendrichs motivaron entre los especialistas una nueva y detallada reelectura de los códices y Relaciones, ya citados, amén de la literatura especializada acumulada hasta el momento sobre los temas en cuestión.

Pero fue debido a las acuciosas investigaciones del norteamericano J. B. Warren, que el conocimiento dio un gran salto no siempre ponderado, o suficientemente difundido entre los estudiosos, al encontrar y publicar posteriormente en 1968 el

(36) Pedro R. HENDRICHS [28]; del mismo autor, Por tierras ignotas. Viajes y observaciones en la región del rio de las Balsas, México, Editorial Cultura, tomo I, 1945; José AlciNa Franch [11], págs. 307-331.

(37) Miguel Othon MendizÁBal [31], págs. 89-118; José CoRona NúÑEz [31]; Relaciones de Michoacán (1541). Relaciones de las Ceremonias y Ritos y Población y Gobierno de Michoacán, Reproducción facsimilar del Mc. c IV de El Escorial, Madrid, Editorial Aguilar, 1956; Relaciones Geográficas (1579-1580). Relaciones Geográficas de la Diócesis de Michoacán, Guadalajara, Editor José Corona Núñez, 1958. 
Legajo 1204 del Archivo General de Indias (38). El contenido del documento en cuestión, conocido mejor como Minas de cobre en Michoacán, por ser éste el título de su publicación original, corresponde a la información reunida por mandato de Vasco de Quiroga, siendo oidor de la Primera Audiencia, para que los reyes de España tuvieran conocimiento de la verdadera situación de las minas de cobre en la Nueva España. El documento, fechado el 15 de octubre de 1533, reproduce la información proporcionada por cinco fundidores indígenas ante escribano real, en donde se asienta que los tarascos tenían sus propias minas de cobre y que las trabajaban mucho tiempo antes de que llegaran los españoles al territorio dominado por éstos. Las principales minas, de acuerdo con el documento, se localizaban en la Guacana, Turicato, Churumuco, Cinagua, $\mathrm{Cu}$ carán, Pungarabato, Guayameo, Tancítaro, Tacámbaro, Coyura, Uruapan, Cucamala, Tepalcatepec, Asuchitlán y Periguán (39).

El siguiente gran descubrimiento fue, precisamente, la ubicación y explotación física de algunas de estas minas prehispánicas, con lo que se cerró un gran ciclo en la historiografía del área mesoamericana, y en especial de la cultura metalúrgica tarasca en el occidente de México.

Un grupo de especialistas de distintas disciplinas, dirigido por Dora María Krasnopolsky de Grinberg (40), llevó a cabo en la década de 1980 un minucioso trabajo de campo en una basta región michoacana, anteriormente ocupada por los ta-

(38) J. B. WARREN «Minas de cobre en Michoacán, 1533», Anales del Museo Michoacano, 2. época, n. ${ }^{\circ}$ 6, Morelia, 1968, págs. 35-48.

(39) Aquí es preciso recordar los resultados a los que arribaron los ingenieros de minas José Haro y Santiago Ramírez a principios de la década de 1880 , y la insinuación velada de que los minerales de cobre, de gran abundancia en la región, pudiesen haber sido explotados por los tarascos anterior a la conquista española. Sin embargo, como hemos visto, y dado que éste no era ni mucho menos la razón y el objetivo de sus investigaciones, sus opiniones pasaron desapercibidas o en su momento carecieron de solidez científica.

(40) D. M. K. GRINBERG, "Minas prehispánicas del Ario, Michoacán», Actas del IX Congreso de la Academia Nacional de Ingenieros, México, 1983; de la misma autora, "Las escorias prehispánicas tarascas de Michoacán", $X$ InterAmerican Conference on Materials Tecnology, San Antonio, Texas, 1985; «La soldadura evidencia de uso entre los tarascos», Metalurgia Moderna, vol. 3, n. ${ }^{\circ}$ 1, 1987, págs. 45-48; [31]; "Tecnología metalúrgica tarasca», Ciencia y Desarrollo, vol. XV, n. ${ }^{\circ} 89,1989$, págs. 37-52.

R. I., 1996, n. ${ }^{\circ} 207$ 
rascos. Apoyándose en un importante conjunto de conocimientos sobre la región de estudio, y en dos documentos posthispánicos del inicio de la Conquista: el Legajo 1.204 del Archivo General de Indias y el Lienzo de Jucutacato, mismos que se refieren a la ubicación de las minas de cobre, dieron con las minas prehispánicas de Churumuco enclavadas sobre la ladera oriental del Cerro de Mayapito, en la zona de la presa del Infiernillo, sobre el río Balsas (41).

Las exploraciones y análisis revelaron que las minas encontradas habían sido trabajadas a tajo abierto; las que no se encontraron derrumbadas mostraban que su tamaño no era superior a los 15 metros de largo por 2 metros de ancho. Su profundidad no excedía los 7 metros en la parte más honda y 3 metros en la menor. Como en el caso de la mina encontrada por Pedro Hendrichs, éstas mostraron todas las evidencias de ser explotaciones sobre los afloramientos del mineral; ésto, aunado al contenido de los terrenos y el comentario de los fundidores indígenas que hablan en el Legajo de piedras verdes, sugiere, de acuerdo con Grinberg, que se trataban de obtener minerales oxidados, tales como azurita y maláquita, además de los óxidos de cobre que seguramente los acompañaban.

Los estudios no arrojaron señal alguna de la existencia de trabas de piedra para impedir el derrumbamiento de las paredes o el deslizamiento del material, mucho menos de trabajos subterráneos. Tampoco se encontraron en las minas prehispánicas evidencias del uso del fuego para quebrar las rocas, que apoyaran la hipótesis lanzada por Hendrichs en los años cuarenta (42). Lo que se encontró, fueron herramientas en las proximidades de las minas: mazos de piedra fragmentados; en una de las minas apareció una mesa de molienda para cuya

(41) Los trabajos de Dora M. K. de Grinberg y de su equipo de investigación multidisciplinário, estuvieron precedidos, también por otro tipo de estudios, como los efectuados por N. GonZÁlez CRESPO, Patrón de asentamientos prehispánicos en la parte central del Bajo Balsas: un ensayo metodológico, México, Departamento de Prehistoria, Instituto Nacional de Antropología e Historia, 1979; Jenaro GonZÁLEZ REYNA [16]; Robert WEST [18]; Donald BRAND [29], págs. 49-169; Rubén MALDONADO, Ofrendas asociadas a entierros de infiernillo en el Balsas, México, Centro Regional del Sureste/Intituto Nacional de Antroplogía e Historia, 1980; María Luisa Horcasitas DE BARRos [29].

(42) D. M. K. GRINBERG [40]; de la misma autora [40], págs. 37-52. 
construcción se utilizó, in situ, una gran masa de diorita, a la que se le aplanó la parte superior. En un rincón de la mesa se nota un canal, que quizá fue usado para desalojar el mineral molido de la superficie y, tal vez, envasado en seco. Próximo al lugar de la mesa, se recogieron una gran cantidad de piedras desgastadas que parecen haberse empleado para moler el mineral. Otro hallazgo, fueron algunos morteros semitransportables, llamados «ticuiches» por los habitantes de la región.

En casi todas las minas prehispánicas se localizaron escorias; en una de ellas se encontraron los restos de una construcción sin argamasa entre sus piedras, lo que hace pensar según los expertos en un tipo de construcción en el que se reducía el mineral.

¿Cómo reducían los indígenas tarascos el mineral? El Legajo 1204, publicado con el nombre de Las minas de cobre de Michoacán, consigna que los fundidores indígenas no conocían las formas en que los españoles obtenían el cobre, pero revela cómo lo hacían ellos. Los fundidores indígenas interrogados en 1533, coinciden en que recogían piedras verdes de las minas, tareas que realizaban las mujeres por no ser una actividad calificada. Una vez recolectado el mineral, era molido en una gran masa de diorita o en morteros semitransportables cerca de las minas, en donde al mismo tiempo se quitaba la ganga (pedazos no metálicos). Molido éste, los fundidores indígenas lo mezclaban con carbón y lo colocaban en un «crisol» o en "pozos poco profundos cubiertos de tierra, revestido con una mezcla de barro y cenizas e intensificaban el calor soplando a través de unos tubos de caña». Usando este procedimiento, según un fundidor indígena, había necesidad de "fundir dos o tres veces para que quede como ha de estar", y pudiera ser usado para labrarlo y uhacer sus herramientas muy provechoso para cortar y labrar sus sementeras» (43).

Los informantes de Vasco de Quiroga señalan que cada fundidor producía un tejuelo de cobre (lingote) diario, de aproximadamente 17 centímetros por 3,5 centímetros; es decir, de

(43) J. B. WARREN [38], págs. 35-48; E. BARRETT, "The King's Cooper Mine: Inguarán in New Spain», The Americas, XXXVIII, 1985, págs. 1-29; D. M. K. GRINBERG [40].

R. I., 1996, n. 207 
4,25 kilogramos de peso. En un mes la producción de un fundidor sería, en teoría, siguiendo este ritmo de producción, de 30 tejuelos, alrededor de 128 kilogramos. Una cuadrilla de diez fundidores produciría al mes 1.300 kilogramos de cobre.

Más que las cantidades de cobre producido, lo que resultaría extremadamente difícil de cuantificar, lo verdaderamente significativo del caso fue el cotejo y cruzamiento de la información acumulada por arqueólogos, etnólogos, geólogos, historiadores, antropólogos, químicos, metalurgistas, etcétera, que vino a despejar la gran incógnita, y demostrar qủe la cultura metalúrgica tarasca usó sus propias materias primas que su entorno ecológico proporcionaba.

Finalmente, debemos decir que los estudiosos han comprobado reiteradamente que los tarascos permanecieron independientes de los aztecas, hasta la llegada de los españoles. Este hecho permitió a los investigadores llegar a la conclusión de que la cultura metalúrgica tarasca se mantuvo menos hibridizada que otras regiones bajo la influencia mexicana, o en la que los comerciantes aztecas intercambiaban objetos de metal, o se desplazaba a los grupos de artesanos de las regiones dominadas a la cabecera del imperio. Lo anterior permite explicar, de acuerdo con Krasnopolsky de Grinberg, Hosler, Pollard y otros (44), dos de las características de la metalurgia tarasca: primera, abundancia de artefactos de cobre y sus aleaciones; segunda, ello implica, desde el punto de vista metalúrgico, un mayor desarrollo de la tecnología en comparación con regiones de Mesoamérica que trabajaban metales nativos como el oro y la plata.

W. Bray, destacó por su parte, al concluir un estudio sobre el metal fino en la joyería del suroeste mexicano, marcadas

(44) D. M. K. Grinberg [40], págs. 39-50; Helen Perlstein Pollard, "The Political Economy of Prehispanic Tarascan Metallurgy», American Antiquity, vol 52, n. ${ }^{\circ}$, The Society for American Archaeology, 1987; Dorothy HosLER, The Cultural Organization of Technology: Cooper Allys in Ancient West México, Paper presented at 5 oth Anual Meeting of the Society for American Archaeology, Denver, 1985; M. ${ }^{a}$ D. Flores dE Auirrezábal y C. A. Quijada LóPEZ, "Distribución de objetos de metal en el occidente de México», Rutas de Intercambio en Mesoamérica y Norte de México, tomo 2, págs. 83-88; Francisca Franco y Angélica MACías, "Metalurgia Tarasca en la Cuenca de Cuitzeo", Anales del Museo Michoacano, 3. a época, n.o 4, Centro Regional Michoacano/INAH., 1992. 
diferencias entre el material tarasco y aquellos del centro y sur de México. Dice que «cuando se presta primero atención en el estilo y la forma y no en la tecnología, el material se destaca por una forma distintiva y diferente de aquella del centro y sur de México» (45). Se trata, pues, de una cultura metalúrgica tarasca distintiva; ciertamente influida desde Centro y Sudamérica, como veremos más adelante, pero con caracteres propios que ha permitido a los expertos concluir que se trata de una cultura metalúrgica fruto de una tradición regional (46).

$$
* * *
$$

¿Cuáles fueron las características de la tecnología implementada en el occidente del México prehispánico? Para responder a esta pregunta, los expertos y especialistas han recurrido, necesariamente, a los conceptos y técnicas analíticas de la ciencia de materiales. Uno de los objetivos de este enfoque metodológico ha sido el de identificar las propiedades particulares del metal que fueron importantes en esa región y las formas en que la tecnología fue estructurada para conseguir esas propiedades. A través de esta línea de investigación inaugurada en los años sesenta, pero sólo generalizada en la década de los ochenta, se alcanzaron los primeros frutos sólidos, que mostraron que el metal primario utilizado en esta región del occidente de México era de cobre, mismo que era aleado con otros metales.

Dorothy Hosler (47), en sus estudios realizados a mediados

(45) W. BRAY, "Fine Metal Jewelry from Southern México», Festeschrift for J. L. Lorenzo, edited by L. Mirambell and J. Lituak-King, México, Universidad Nacional Autónoma de México, 1984.

(46) S. Gerenstein and Helen Perlstein Pollard [16]; Helen Pelstein PoLLARD [44].

(47) Dorothy Hosler, The Cultural Organization of Technology: Cooper Allys in Ancient West México, Paper presented at the 5 oth Anual Meeting of the Society for American Archaeology, Denver, 1985; de la misma autora [16], y "The cultural organization of technology: Cooper alloys in ancient West México", Precolumbian American Metallurgy, Special Publication of the New World Metallurgy Symposium, Forty-Fifth International Congress of Americanists, Bogotá, Banco de la República, 1986, págs. 67-86; "The Metallurgy of Ancient West México", The Beginning of the Use of Metals and Alloys, Edited by Robert Maddin, MIT. Press, Cambridge, 1988, págs. 328-343. 
de los años ochenta, concretó un análisis técnico de aproximadamente 400 objetos y artefactos metálicos de una colección de más de 4.000 resguardados en el Museo Regional de Guadalajara, México. Con base en los datos obtenidos, propuso una tipología de las características tecnológicas desarrolladas en esta región mesoamericana.

Una de estas características es la de los métodos utilizados para manufacturar los objetos. Los dos métodos comunes para moldear los metales incluyen fundición y martillado. Cuando el metal es fundido, es calentado a temperaturas en las que se vuelve líquido, es vertido en estado líquido dentro de un molde y luego se solidifica en la forma del molde. Los objetos martillados en contraste, son formados generalmente martilleando el metal en estado sólido, estando frío o caliente. La identificación de estas técnicas de fabricación se consigue examinando la microestructura del metal del que está hecho el artefacto.

Otra característica de la tecnología que es clave para identificar las propiedades importantes del material son los metales y aleaciones particulares utilizados. Los metales frecuentemente utilizados en las metalurgias no industriales incluyen cobre, hierro, oro, plata y plomo. Las aleaciones -mezclas de dos o más de dichos metales- incluyen cobre-plata, cobre-oro, las dos aleaciones de bronce -cobre-arsénico y cobre-estaño- y otras.

Otra caračterística importante de la tecnología es el diseño del objeto, ya que ciertas propiedades se manifiestan a través del diseño. Una pieza metálica, por ejemplo, puede hacerse de una amplia gama de tipos de aleación y, en teoría, funcionará exitosamente ya que todas esas composiciones le dan suficiente elasticidad -una propiedad fundamental de una pieza- al material. Si su diseño es tal que al usarla el metal es presionado fuertemente, sin embargo, la pieza puede fracturarse y fallar. Por lo general un número de combinaciones específicas de diseños y composiciones de aleación pueden convertirse en un implemento funcional; la selección repetida de combinaciones trabajables particulares refleja soluciones culturales estandarizadas para cada problema individual de diseño (48).

(48) André Clement [35], págs. 84-91; Dorothy Hosler, «La metalurgia en la antigua Mesoamérica: sonidos y colores del poder», Mario Humberto Ruz (ed.), Semillas de Industria. Transformaciones de la tecnología indigena en las Américas, México, CIESAS., 1994; D. M. K. GrinBERG [4]. 
Las investigaciones modernas, apoyándose en análisis de laboratorio, han encontrado que las aleaciones efectuadas en la región tarasca incluyeron cobre-estaño, cobre-arsénico, cobreplata y cobre-arsénico-estaño. El cobre y sus aleaciones se utilizaban para hacer objetos que eran moldeados por fundición, utilizando la técnica de fundición a la cera pérdida, como también para objetos que eran martillados tanto en caliente como en frío. Los objetos fundidos a la cera pérdida más importantes eran las campanas. Aparecen en variedad de diferentes tamaños y tipos. Los objetos martillados en caliente y frío incluyen anillos, hachas, azadones, anzuelos, agujas de coser y pinzas de varios tipos.

Según los estudios de laboratorio realizados por Dorothy Hosler, el $35 \%$ de los objetos de metal sometidos a escrutinio contienen las dos aleaciones de bronce -cobre-estaño y cobrearsénico- (49). Sin embargo, a diferencia de otras regiones del mundo en donde dichas aleaciones fueron utilizadas ampliamente para herramientas, en el occidente de México fueron empleadas más frecuentemente para otros propósitos. En definitiva, las aleaciones fueron utilizadas para fabricar tres clases de objetos: anillos, pinzas y campanas. En ellos, la dureza no constituye una propiedad importante para el funcionamiento de estos artefactos. La resistencia es igualmente poco importante en las campanas y anillos, y aunque es relevante en el caso de las pinzas, parece no ser la propiedad que motivó el uso particular de estas aleaciones. Las dos aleaciones de bronce fueron utilizadas en busca de propiedades bastante distintas a

(49) Dos propiedades del bronce enfatizadas por las metalurgias de muchas áreas del mundo son la resistencia y la dureza. Ambas son esenciales en herramientas de cortar. La resistencia es la habilidad del metal para absorber impactos sin requebrajarse. La dureza es la capacidad del metal de oponerse a la deformación: determina el campo de materiales que puede ser cortado con una herramienta particular. Cuando estaño o arsénico son aleados con el cobre la dureza del metal aumenta drásticamente si la aleación es martillada en frío. Por ejemplo, la adición de un $5 \%$ de estaño al cobre -si el metal es trabajado en frío- puede hacer que la aleación resultante sea tan dura como ciertos aceros. Los cobres arsenicales dan una dureza que es casi comparable. Ambas aleaciones de bronce han sido ampliamente utilizadas para herramientas pesadas en la región Andina de América del Sur y también en las metalurgias del Viejo Mundo. 
aquellas de las sociedades con herramientas. Estas fueron: color y resonancia. Según los especialistas y expertos, en ello radica la singularidad de la cultura metalúrgica tarasca, y su diferencia con relación a otras sociedades y culturas presentes en Mesoamérica y la región de los Andes, y su contribución al desarrollo de la metalurgia prehispánica.

\section{Algunos rasgos de la influencia SUdAMERICANA EN la metalurgia del occidente de MÉxico}

La más antigua referencia histórica sobre la influencia sudamericana en la cultura metalúrgica de Mesoamérica, proviene de la carta que Rodrigo de Albornoz dirigió al Emperador Carlos V, el 15 de diciembre de 1585. En ella Albornoz se refiere a Zacatula como puerto de intercambio entre indígenas sudamericanos que "venían en unas grandes piraguas y les traían allí cosas gentiles de rescato y llevaban ellos otras de la tierra y que algunas veces, cuando la mar andaba brava que suele haber grandes olas en aquella parte del sur más que en otra parte ninguna, se quedaban acá cinco y seis meses...» (50).

Por otra parte, la escasa documentación histórica, es decir, las más antiguas fuentes históricas, aludían a la explotación del cobre durantê la Colonia (51). Pero existían pocas evidencias

(50) Rodrigo de Albornoz, Colección de documentos inéditos relativos al descubrimiento, conquista y organización de las antiguas posesiones españolas en América y Oceanía. Carta de 15 de diciembre de 1585, Madrid, tomo XIII, 1870.

(51) Áutores de la época, refieren a Michoacán como una región muy favorecida por la naturaleza, con tierras húmedas y fértiles para la agricultura y la ganadería, abundantes ríos y lagos, y ricos minerales: Diego DE BASALENQUE (1673), Historia de la Provincia de San Nicolás de Tolentino de Michoacán del Orden de N.P.S. Agustín, 1577-1651, Introducción y Notas de José Bravo Ugarte, México, Editorial Jus, 1963; Alonso DE LA REA, Crónica de la Orden de Nuestro Seráfico Padre San Francisco provincia de San Pedro y San Pablo de Michoacán en la Nueva España, México, Imprenta de J. R. Barbedillo, 1882; Pablo de la Purísima Concepción Beaumont (1873), Crónica de Michoacán, México, Talleres Gráficos de la Nación, tomo III, 1932; Francisco ARNALdo Y SASSY, Demarcación y descripción de el Obispado de Michoacán y fundación de su Iglesia Cathedral, Biblioteca América, vol. 1, Humber 1, September, 1982, University of Miami Station. Coral Gables, Florich. Collection of Americana Ms. 1106, Hemberry Librery of Chicago; Francisco DE AJOFRIN, Diario de viaje 
sobre esta actividad anterior a la llegada de los españoles al occidente de México. Sin embargo, las investigaciones arqueológicas y etnohistóricas de las décadas de 1930-1950, llegaron a un punto definitivo del problema. Para entonces estaba claro que los artefactos metálicos estaban profundamente imbricados en la organización social y cultural de la región tarasca. ¿Cuál era entonces su origen, cuál su trayectoria?

En 1946 los resultados de investigación de los etnólogos franceses Paul Rivet y Henry Arsandaux cambiaron por completo el problema en cuestión. Ahora las nuevas preguntas apuntaban al hecho de una influencia de Centro y Sudamérica sobre el occidente de México. Para Rivet y Arsandaux no cabía la menor duda de que por lo menos las técnicas metalúrgicas se habían introducido a Mesoamérica provenientes de Colombia, Ecuador y Perú, vía marítima (52). Lo anterior despejaba

que hizo por América Septentrional en el siglo XVIII, por..., México, SEP/Cultura, 2 vols., 1986.

(52) Los franceses llegaron a estas conclusiones, apoyándose en los siguientes argumentos: «Sí se compara la metalurgia de la costa peruana con la metalurgia de México, se constatarán entre ellas similitudes extraordinarias, por no decir una identidad completa... Este tráfico se hacía al amparo de balsas... El gran hiato que existe entre la costa peruana y del Ecuador por un lado, y México por el otro lado, excluye la hipótesis de una transmisión por vía terrestre, y lleva a pensar en una transferencia por vía marítima... El hallazgo en las tumbas ecuatorianas y peruanas de conchas marinas procedentes de Centroamérica, el descubrimiento de hachas, monedas mexicanas (sic) en la costa de Colombia, del Ecuador y del Perú... confirman los fundamentos históricos. La identidad de la metalurgia mexicana con la metalurgia costera peruana, su poca antigüedad, su limitada difusión, en contraste con la perfección y multiplicidad de sus técnicas... todo, en una palabra, impone la conclusión, que la industria de metales ha sido introducida a México ya enteramente concluida y en posesión de todos sus medios técnicos, y que esta importación ha llegado del litoral peruano». «Es evidente -dicen los etnólogos franceses- que esta transferencia de conocimientos complejos mediante relaciones pacíficas, de naturaleza esencialmente comercial, no se hizo en un sólo tiempo, y que fue el resultado de una infiltración lenta y progresiva. Como sabemos que la metalurgia costera (nor)peruana no estuvo en plena posesión de su arsenal y de todas sus técnicas sino a partir del siglo IX, debemos inferir de ello, que la transferencia de esta industria a México sólo pudo realizarse después de esa fecha. Sabemos, por otra parte, que el cobre y el oro se desconocían en México durante el período de Teotihuacán, y que en Monte Albán el cobre no aparece hasta el período IV. Por consiguiente, es seguro que la metalurgia mexicana sólo comienza antes del siglo IX». Paul RIVET et Henry ARSANDAUX [10], págs. 52-172.

\section{R. I., 1996, n. ${ }^{\circ} 207$}


varias incógnitas, que se habían bosquejado, pero no resuelto. Una de ellas estaba referida al por qué se habían desarrollado la técnicas mineras primeramente en la región de la costa del Pacífico (mexicano), Guerrero y Michoacán, y en el segundo lugar, por qué hizo su aparición de súbito, dueña de técnicas muy lentamente alcanzadas antes en Sudamérica.

Los resultados de las investigaciones, particularmente las realizadas por Paul Rivet, venían a alterar los contenidos y el futuro de los conocimientos que se tenían hasta entonces sobre el origen y el desarrollo de las técnicas metalúrgicas del occidente de México, en concreto, sobre la metalurgia tarasca. Rivet arribó a estas conclusiones después de más de 30 años de acuciosas investigaciones en Sudamérica y en México, empleando el método comparativo (53).

Los planteamientos de Rivet y Arsandaux, aún están presentes en el origen de la polémica actual. Los etnólogos franceses llegaron a la conclusión de que la metalurgia y la orfebrería del área mesoamericana, que evidentemente es mucho más tardía que la del área andina, pudo haberse originado en la costa peruana en función de la falta de antecedentes locales, la similitud de técnicas, etc. Otros estudiosos anotaron que pudo ser la consecuencia de los intercambios comerciales e influjos culturales recibidos en el área sur de Mesoamérica, desde Panamá y Costa Rica (54). Esta última explicación fue recogida por José Alcina Franch en 1970 por parecerle, a la luz de la información de ese entonces, más coherente con lo que se sabía de las mutuas relaciones entre Mesoamérica y la zona mencionada de Centroamérica (55).

La mayoría de los especialistas, como Rivet, Arsandaux, Pendergast, Willey, Meighan y Mountjoy, y otros, están de acuerdo

(53) Paul Rivet, "Étude sur l'archéologie mexicaine», Comptes rendus de l'Academie des Inscriptions et Belles-Lettres, París, 1921, págs. 337-340; del mismo autor, "Recherches sur la métallurgie mexicaine», L'Anthropologie, París, 1921, págs. 521-522; "Nouvelle note sur la métallurgie mexicaine», L'Anthropologie, tomo XXXIII, París, 1923, págs. 63-85; en colaboración con Henry ARSANDAUX [10].

(54) Alfonso CASO, "Lapidary work, gold work and copper work from Oaxaca", Handbook of Middle American Indians, vol. 3, Austin, Texas, 1965, págs. 895-931.

(55) José Alcina Franch [11], págs. 307-331. 
en que la metalurgia del occidente de México no fue nativa, sino que fue introducida del Centro y de Sudamérica, probablemente por vía marítima (56). Más recientemente Adam Szaszdi Nagy, en un documentado estudio sobre las rutas del comercio prehispánico de los metales, reconstruye los circuitos comerciales del metal en una amplia área del Nuevo Mundo, desde las islas del Caribe, Centro y Sudamérica, y la introducción e influencia de los metales, el conocimiento metalúrgico y tecnológico en el occidente de México. Pero Szaszdi va más lejos que sus antecesores, no sólo coincide con ellos en cuanto a la influencia metalúrgica sobre el occidente mexicano, sino que concluyó su estudio sosteniendo que "prácticamente todo el cobre y toda la plata que los conquistadores hallaron en los territorios controlados por los tarascos procedían de las minas de Chile, Bolivia y Perú. Los habían llevado los balseros ecuatoriales, y un buen indicio de esto son las hachas de monedas -que incluso aparecen en el inventario de tributos del Códex Mendoza- otrora conocido como 'típicamente mexicano', cuando su lugar de emisión era la Costa del Ecuador» (57).

(56) Paul Rivet et Henry Arsandaux [10], págs. 52-172; David Pendergast [29], págs. 520-545; J. MounTJOY [29], págs. 26-42.

(57) Más adelante señala que «en cuanto a las minas de plata en territorio de Cazoncín, lo más probable es que no las ha habido, en buena medida porque no es una zona de yacimientos argentíferos. Es verdad -añade-, que la parte de la Nueva España donde más plata obtuvieron los conquistadores fue allí: la llamada 'plata de Michoacán' tenía un alto contenido de cobre, empero, por lo que es obvio que se trataba de una aleación. No obstante, a la fama de tales riquezas, muchos españoles pasaron de México 'a las minas de $\mathrm{Mi}$ choacán' en 1524; y al año siguiente, uno llamado Morcilla diz que encontró una. López de Gamara escribio: 'Hay en este reino (de Michoacán) muchas minas de plata y de oro bajo (sic), y el año 1525 se descubrió en él la más rica mina de plata que se había visto en la Nueva España; y por ser tal, la tomaron para el Rey sus Oficiales, no sin agravio de quien la halló. Más quiso Dios que luego se perdiese o acabase; y así lo perdió su dueño, y el Rey su quinto, y ellas la fama'. Torquemada recoge el dato, diciendo que no se sabía si la mina desapareció por haber caído encima un cerro, si los indios la cubrieron 'con tanto artificio, que nunca más se vido rastro de ella', o si 'fue juicio y permisión de Dios que se desapareciera, por aversela tomado al que la avía descubierto'. El caso es que no es muy exacto aquí Torquemada, al decir que 'Michoacán es la más rica de metales de toda Nueva España, así de cobre y estaño, como de oro y plata'. Cuando escribía esto - dice Adam- a fines del siglo, no debía haber afirmado tal cosa de la plata, en buena conciencia». Adam SZASZDi NAGY [35], pág. 123.

\section{R. I., 1996, n. 207}


Los últimos estudios realizados sobre esta problemática, han puesto a consideración dos cosas. La primera, que los pobladores del occidente de México, es decir, la sociedad tarasca principalmente, trabajaron sus propias minas, como se vio en el apartado anterior; la segunda, que efectivamente existió una influencia histórica del Centro y Sudamérica sobre la cultura metalúrgica mesoamericana. Empero, dada su complejidad, este aspecto del fenómeno deberá ser objeto de otro estudio más detallado en razón de que su tratamiento requiere de un espacio mayor al disponible y porque desborda las pretensiones de esta investigación. No obstante debo decir que los expertos mesoamericanistas han alcanzado niveles de conocimientos hasta entonces insospechados, sobre esta influencia histórica. Desde luego, ello ha sido posible gracias al trabajo multidisciplinario, y al afán de priorizar en todo momento el avance del conocimiento.

Parece quedar claro, sin embargo, que en las culturas metalúrgicas de Centro y Sudamérica se había usado el metal por lo menos durante unos mil años antes de que hiciera su aparición en el occidente de México. Los pueblos andinos usaban el cobre, la plata y el oro y sus aleaciones para fabricar objetos suntuarios, utilizando complejas técnicas de enriquecimiento de la superficie de manera que los objetos de hojas metálicas, hechos de aleaciones cobre-oro y cobre-plata, parecieran plateados y dorados. Usaban, asimismo, profusamente los dos bronces para herramientas e implementos agrícolas: agujas, punzones, hachas, azadas y puntas en instrumentos para excavar.

Según los estudios comparativos de las tecnologías centro y sudamericanas con el primer período de la metalurgia del occidente de México (que data de una fecha imprecisa entre el año 700 y 1200 a.C.) iniciados por Rivet y Arsandaux, y continuados por expertos mexicanos, estadounidenses y europeos, revela que todas las características de esta etapa metalúrgica derivan de las dos culturas metalúrgicas meridionales. Durante este período, la metalurgia del occidente mexicano muestra una semejanza más pronunciada con la del sur de Ecuador. Los orfebres tarascos utilizaban el cobre para hacer campanas, pinzas, agujas, aros y otros objetos, como hachas y punzones. En el sur de Ecuador la gente hacía este mismo tipo de objetos, con iguales 
características de diseño y mediante las mismas técnicas de fabricación. Desde luego, como es obvio, los artefactos ecuatorianos son anteriores a sus contrapartes mexicanas.

Según los especialistas, fue el conocimiento, no los objetos como sugiere Szaszdi Nagy, lo que se importó al Occidente: conocimiento de las tecnologías de fundición, de los dos tipos de minerales y menas, de técnicas de fabricación y de las clases de objetos que podían hacerse con metal, que eran, claro está, el mismo tipo de objetos que se producían en Ecuador, en el sur de Centroamérica y en Colombia (58).

Durante la segunda fase de la metalurgia del occidente de México, más o menos desde el año 1200 hasta la llegada de los españoles, el repertorio técnico básico que había definido la tecnología se amplió sustancialmente. El cambio más importante y significativo fue que la gente de esta región mexicana comenzó a utilizar aleaciones de los dos bronces, así como una aleación de cobre-plata. Aparecieron también nuevos diseños de artefactos -agujas, pinzas, campanas, entre otros- que eran subtipos de los hechos en períodos anteriores y cuyas características volvían imperativo el uso de estas aleaciones por razones técnicas.

Dorothy Hosler, Helen Perlstein Pollard, D. M. Krasnopolsky de Grinberg, entre otros, aunque dejan abierta la posibilidad de que algunos de esos objetos terminaran por llegar al occidente de México sostienen, en contrapartida de Szaszdi, que lo que se importó fue el conocimiento y las técnicas que la gente incorporaba, dándoles luego su propia forma, de manera que la tecnología expresara actitudes frente al material que surgían de los intereses e inquietudes locales (59).

Por último, las investigaciones arqueológicas, etnohistóricas, antropológicas e históricas han coincidido en que la característica distintiva de la metalurgia que se desarrolló en la región tarasca y áreas de influencia, fue que más del $80 \%$ de todos los objetos hechos de metal eran artículos que de un modo u otro transmitían el estatus y el poder de las élites. En esta región, el metal más que para hacer herramientas, aunque llegaron a

(58) Dorothy HosLer [16].

(59) Helen Perlstein Pollard [44]; D. M. K. De Grinberg [40], págs. 37-52; Dorothy HOSLER [16].

R. I., 1996, n. $^{\circ} 207$ 
construirse, era un material sagrado -y se utilizaba en objetos que gozaban de ese carácter- de las élites, de los sacerdotes y de los gobernantes que lo usaban. Estas actitudes eran transmitidas por medio del realce que daban dos propiedades poco usuales de los nuevos materiales: su sonido y su color (60).

El color, por supuesto, era una propiedad que había atraído a la gente de los Andes, en particular el del oro y de la plata, asociados con las deidades solares y lunares. Los pobladores del occidente mexicano también estaban interesados en los colores del metal, en especial del oro y de la plata, por las mismas razones (61). No obstante, obtenían esos colores mediante el recurso, extraordinariamente técnico, de usar dos aleaciones sobre todo, de naturaleza utilitaria: el bronce de cobre-estaño y de cobre-arsénico. Muchos de los objetos suntuarios más importantes de las élites se hacían del primer tipo de bronce, pero con tal concentración de estaño que los objetos eran, literalmente, dorados. Las pinzas de concha, por ejemplo, símbolos de vocación sacerdotal y de buen carácter, se elaboraban con concentraciones de estaño al $12 \%$, bastante más elevadas de lo que era mecánicamente necesario para lograr el delicado diseño de la concha. La elevada concentración de estaño le confería un color dorado al metal de las pinzas, prestándole simbólicamente a los sacerdotes que lo llevaban, el poder y el carácter. sagrado de la deidad solar. Campanas y aros también comuni-

(60) Relaciones de Michoacán (1541). Relaciones de las Ceremonias y Ritos y Población y Gobierno de Michoacán, Madrid, Reproducción fascimilar del Ms. c IV de El Escorial, Aguilar, 1956; Daniel RuBín DE LA BoRbolla [28], págs. 125-138; Rafael ORELlanA, Informe de trabajo de consolidación efectuados en Tzintzuntzan, Michoacán, México, Departamento de Monumentos Prehispánicos, Instituto Nacional de Antropología e Historia, 1946; Rubén MALDONADo [41]; S. Gorenstein y H. P. Pollar [46]; Marcia CASTRo LEal, "Importancia de la metalurgia en Michoacán durante el post-clásico Tardío", Boletín del CERM-LC, junio de 1983; Francisca Franco y Angélica MACÍAS [44].

(61) Jean BERTHELOT, "L'Exploitation des Métaux Précieux au Temps des Incas", Annales, vol. 33, n.os 5-6, París, 1978, págs. 948-966; Johanna BRoDA, "Astronomy, Cosmovision and Ideology in Prehispanic Mesoamerica", Anthony F. AVENI and Gary URTON, Ethnastronomy and Archaeoastronomy in the American Tropics, New York, The New York Academy of Scientices, 1982, págs. 81-109; Relaciones de Michoacán (1541). Relaciones de las Ceremonias y Ritos $[60]$. 
caban de una manera simbólica la santidad y el poder de las élites, por medio del color; los dos tipos de objetos eran de bronce, con estaño presente en altas concentraciones de hasta un $23 \%$, lo que les confería un color dorado brillante (62).

Tal vez lo más fascinante de los muchos logros espectaculares de estos orfebres del occidente de México, es el modo poco usual como utilizaban el bronce hecho de una aleación de cobre-arsénico. El cobre-arsénico se usaba en bajas concentraciones en implementos como agujas y punzones, al igual que en otras muchas partes del mundo. Pero estos orfebres también empleaban arsénico, en concentraciones de hasta $24 \%$, en ciertos diseños de campanas elaborados con el método de cera perdida. El resultado: los objetos metálicos adquirían un color plateado, que se asociaba con la deidad lunar.

\section{Consideraciones Finales}

A través del análisis de laboratorio y del barrido atómico, que incluyen estudios cuantitativos y cualitativos de composición química; estudios de estructura física; pruebas de dureza y estudios simulados en condiciones de tensión y de deformación de ciertos tipos de artefactos, se ha podido determinar, con escaso margen de error, que la tecnología metalúrgica tarasca era sofisticada y versátil. Que los orfebres del occidente

(62) Esto explica por qué los españoles creyeron que los objetos y artefactos metálicos que los tarascos les suministraron en un primer momento de la Conquista, se trataba de metales preciosos. Poco después cayeron en la cuenta de que el oro y la plata tarasca era de baja ley, o que eran mezcla de oroplata y plata-cobre. El propio Hernán Cortés recoge esta impresión en la Tercer Carta de Relaciones (1522), y señala que al llegar los españoles a la ciudad principal de Huicicila «les dieron hasta tres mil marcos de plata envuelta en cobre, que sería media plata, y hasta cinco mil pesos de oro, asimismo envuelto con plata, que no se le ha dado ley, y ropa de algodón y otras cosillas de las que ellos tienen". El propio Nicolás León, uno de los primeros etnólogos mexicanos que emprendió el estudio de la sociedad tarasca a finales del siglo pasado, difundió la creencia de que los objetos y artefactos metálicos eran de oro y plata, y que algunos eran de cobre. Esta idea se mantuvo en vigor hasta los años cincuenta más o menos. Ver: Hernán Cortés, Cartas y Documentos, México, Editorial Vargas Rea, 1943; Nicolás León [18]; Daniel RU. Bín DE la Borbolla [28]; David Pendergast [29], págs. 525-545. 
de México fabricaron una variedad de objetos, incluyendo herramientas y artefactos simbólicos, para lo que utilizaron cobre y sus aleaciones y una variedad de técnicas de manufactura. Este procedimiento analítico (análisis de laboratorio), apoyado fundamentalmente en los avances científicos de la arqueología, la etnohistoria, la antropología y las más recientes revelaciones históricas, ha puesto al descubierto la presencia cultural en esta región mesoamericana de un sólido y consistente conocimiento sobre las relaciones entre las propiedades de aleaciones y un control sistemático de las propiedades aptas para funciones particulares. El uso de dos bronces -cobrearsénico y cobre-estaño- era general. Ciertas propiedades de las aleaciones de bronce fueron particularmente enfatizadas en la metalurgia del occidente de México. La adecuada selección de tales propiedades refleja actitudes culturales respecto al uso apropiado del material, e ilustra la influencia de la cultura en todos los niveles con relación a la organización del comportamiento tecnológico.

Ahora bien, los tarascos como los mixtecos, zapotecas, mayas y aztecas acumularon importantes cantidades de metales en forma de objetos o artefactos en torno de los palacios, templos, tumbas y otros lugares sagrados. Con la llegada de los europeos al continente, cambió el significado y valor de esta actividad. Por espacio de tres siglos, los españoles se constituyeron en beneficiarios de la riqueza de la Nueva España.

La primera remesa de "oro y plata» que los españoles remitieron a la Corona, provino del saqueo efectuado en esos lugares. La primera cantidad importante de "plata» fue tomada del territorio tarasco; los objetos y artefactos de "plata», usualmente bajos en plata y mezclados con cobre, o resultado de las aleaciones cobre-arsénico y cobre-estaño, en su gran mayoría fueron fundidos en grandes pedazos y enviados a España en los primeros años de la década de 1520 .

Como las huestes de Hernán Cortés "tenían sed de oro", más no de cobre, y dado que la plata y el oro tarasco era de baja ley porque eran el resultado de las aleaciones con el cobre, o como lo dice el propio Cortés, «la plata envuelta en cobre" y el "oro asimismo envuelto con plata», los españoles se dedicaron a buscar los yacimientos de donde se extraían los metales preciosos. Por estas razones, las minas de cobre 
permanecieron momentáneamente en manos de los nativos. Sin embargo, con el paso de los años fueron despojados de sus bienes.

Durante la colonia el cobre fue extraído principalmente de las minas de Inguarán y lugares aledaños; una de las regiones cupríferas mejor conocidas en la época prehispánica, explotada ya por los tarascos antes del contacto, y hoy en día uno de los mayores depósitos minerales de México en donde se concentra aproximadamente el $20 \%$ de las reservas de México. Por su importancia estratégica, la corona española mantuvo el monopolio sobre este mineral hasta comienzos del siglo XIX.

Ignorance of Tarascan metallurgical culture has caused untenable omissions, overstatements and historical errors of fact. This historiographical essay calls attention to this metallurgical culture, which -within the Mesoamerican context- had an extensive knowledge of the work with metals, particularly copper and it alloys; this knowledge was superior to that of regions familiar with the work of native gold and silver. 